\title{
THE CONCEPT OF A MEDICAL INFORMATION SYSTEM BY RATE OF USE (CHEBHOSP)
}

\author{
Mohammad Ali Cheaito $^{1}$, Marwan Cheaito ${ }^{2}$ \\ ${ }^{1}$ Computer Science Department, Hariri Univeristy Campus, Lebanese University, Faculty \\ of science I, Beirut-Hadath Lebanon \\ ${ }^{2}$ Computer Science Department, Lebanese University, \\ Faculty of science V, Nabatieh Lebanon
}

\begin{abstract}
The objective of our study is to focus on the basic concepts of the medical information systems used for the management of IT information taking place in a hospital center and to share the information in databases depending on its use [2]. Nowadays, many softwares exist for the management of information in a hospital. The professional applications are oriented towards invoicing and accounting, while our application focuses on the systems used in a hospital center such as system of medical services, accounting system, storage system, human resources system, and administrative system (Figure 1)... These systems are considered as subsystems which make up the global system [1]. Our hospital information system is based on different the subsystems for the management of: laboratory results, clinic, images, pharmalogical, and pathological results[8]... So, this rate of huge information must be handled by a database management system like SQL [4,5], and its concept must be detailed using a language like UML [6]. In addition, the graphical user interface (gui) [19] is essential to complete our work, by using the software Visual Basic [10, 11], in order to achieve our software the manipulation of data must have a calibration between the execution time and the amount of data storage[14,15,20]. Hence, the distribution of databases is done according to their rate of use is an encouraging solution
\end{abstract}

\section{KEYWORDS}

Hospital Information System, Patient, Databases, SQL, Hospital, Distributed information, Medical.

\section{INTRODUCTION}

Our work will in general be on the edge between informatics and medicine. This arises the question of use of the technologies of the information and the communication aiming to improve medical practices. The science of processing medical information affects deeply the medicine Therefore, the medical information system is the one containing many subsystems [27] (Figure 1) that communicate with each other by using patient identity [13]. This information should be distributed by a set of databases according to the constraints and effective criteria, allowing to manipulate the data in a time by considering the increase and performance of technology according to material and software levels and together with the rate of necessary information needed to satisfy the answers of all the questions put by the actors of Hospital Information System (HIS). The hospital is a place where the rate of use of information is an important parameter for the partition of archiving the information. 


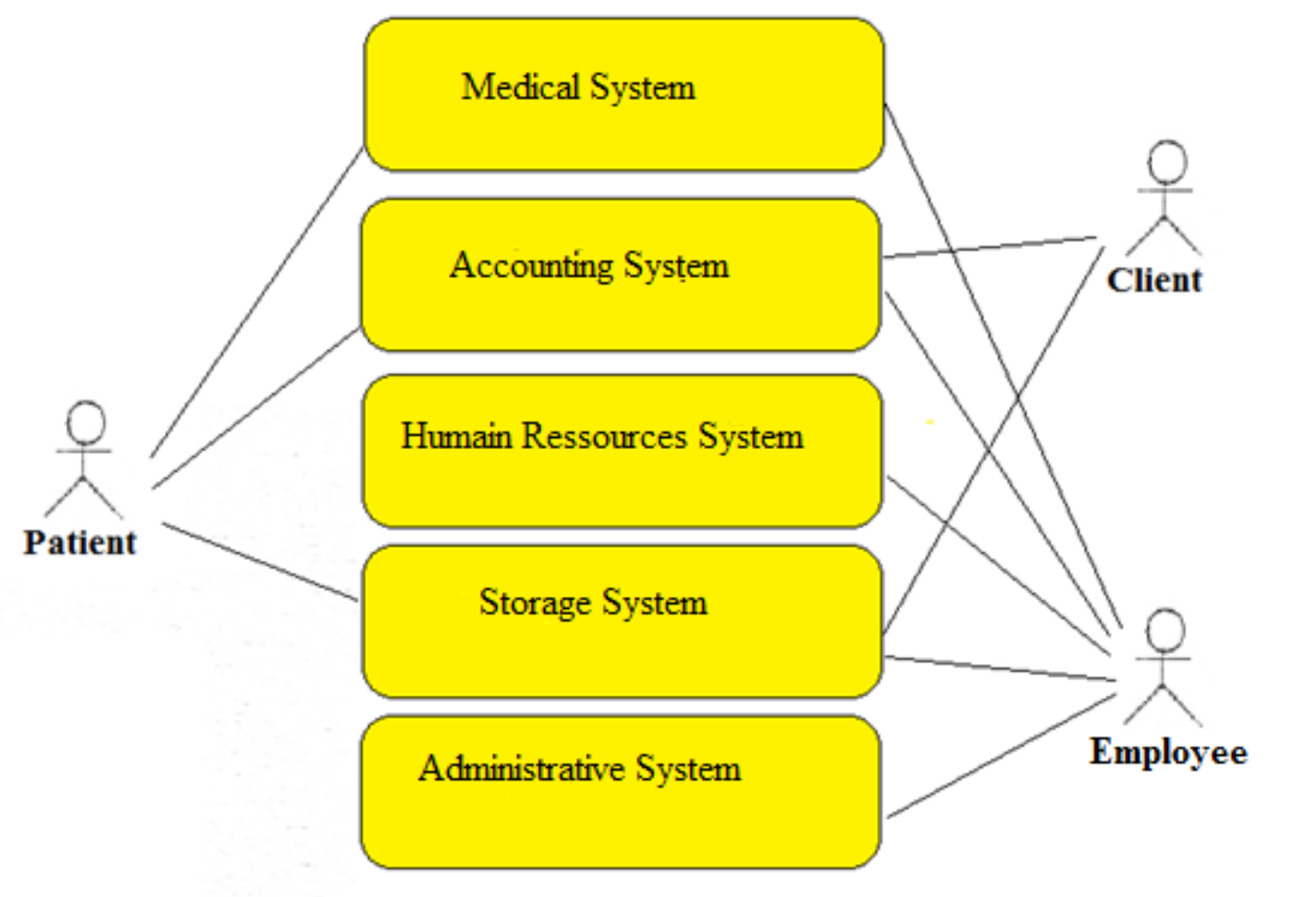

Figure 1: Use case diagram of global hospital information system

Why a science of medical information?

Approaching the question by a series of interrogations. How to store and reuse medical information? How to model medical knowledge so that it can be exploited without ambiguity? Can we imagine a processing information system that is able to manage all medical specialties? The generated information by a hospital can be extremely useful information in a careful context.

\section{PATIENT IdenTIFication}

The information systems assign a unique number for the identification of patients. This number is called the unique identity in the considered identification domain. This domain defined by the grouping of hospital information systems (GMHIS) within a health center allows all the applications to give the same identity for the same patient. It is clear that the multiple methods can be proposed for assigning a unique identity to the same physical person.

In most HIS, the patient identity is an information that respects the criteria given by «The American Standards for Testing and Materials » (ASTM) [12], which is a group of information (characters) which from on hand belongs to personal information and on the other hand give information allowing simple manipulation of data using queries put in the relational database management system (RDBMS) [7].

In our case, the patient identity is a unique number that will be first assigned to a patient in a hospital center as a primary key ( i.e. unique non-duplicate key), and then it will be assigned to this patient for each entrance to the hospital center as a foreign key (i.e. a reference key for the primary key) (Figure 2). 

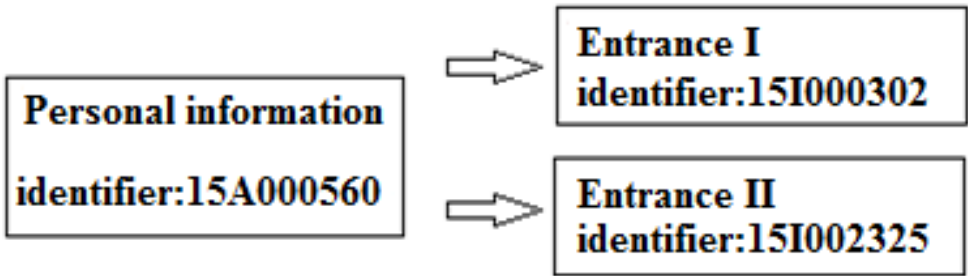

Figure 2 Primary key and foreign key of a patient

Personal information and criteria given by [12] will be respected and assured by the link between primary key and the personal information that are necessary to assure a unique identity of the patient (Figure 3).

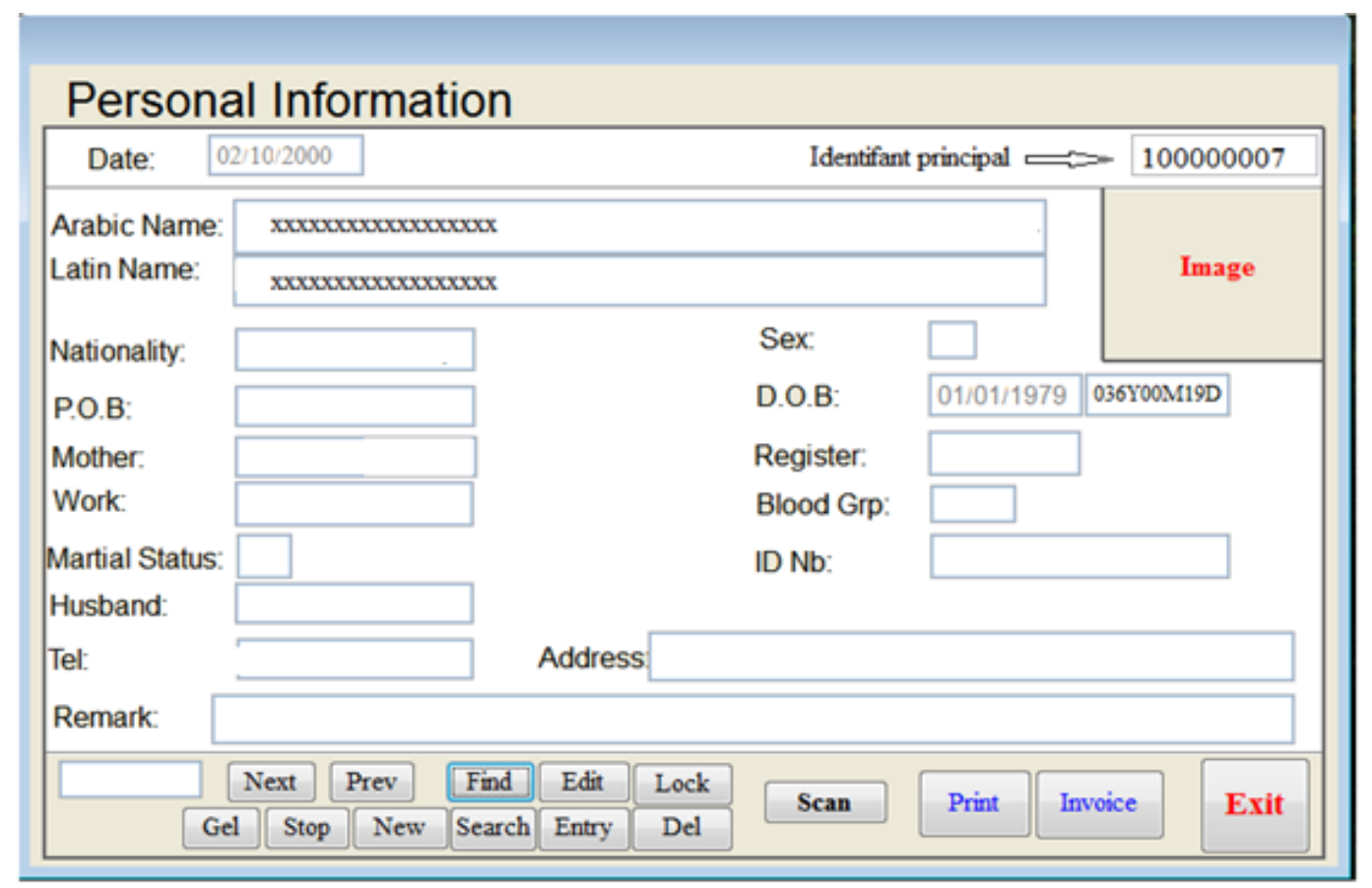

Figure 3 Personal information needed to identify a patient (done by software CheBHosp)

\section{THE EVOLUTION OF THE ARCHITECTURE OF HEALTH INFORMATION SYSTEMS (HIS)}

The architecture of health information systems followed the same evolution as other domains (banks, industries, etc...). By a horizontal approach (a centralized architecture in the 70s) where all information is once caught and is accessible through all posts, to a vertical approach (by department) where each department has its proper application. Nowadays, the architecture of HIS tends to be distributed and applications are integrated the ones to the others by an approach of service-oriented of grid type. For example, university hospitals of Genève were the first allowed to put a service-oriented architecture [3] by using a hospital function and avoiding the vertical approach. 
The computerization of health care facilities has a socio-economic aspect. In fact, technical information improves inter-service communication, and pushes forward the administrative management of a hospital, the management of a pharmacy or radiology. To achieve these objectives, we have to collect and store medical information to be able to query and use it for analysis.

In this paper, we are particularly interested in the implementation of necessary tools and methods to share the information that has a known meaning and quality. The data and knowledge are stored in information systems according to their specific structure. The way information is stored depends on its use.

Definition: an entity (table) is classified as a constant entity (constant table) when the number of occurrences (records) does not change over time. For example: the entity ICD10 (International Classification of Diseases), entity of doctors, entity of drugs are classified as constant entities.

Definition: the information is classified as active information if its consultation or its manipulation will be done in a short period of time. For example: information about a patient that are used for the treatment in a hospital center, are classified as active information.

Definition: the rate of use $\mathbf{n} \%$ of a database is a natural number that represents the percentage of manipulating and consulting of a set of information.

Remark: the rate of use of active information is equal to $100 \%$. In contrast, the rate of information of patients leaving hospitals before more than 10 years id equal to $1 \%$.

\section{Partition of information}

Nowadays, to make analysis of data, it is necessary to integrate the data in different services, and to implement technical solutions to make a quick interrogation of a huge amount of data [9]. The architecture of HIS will be characterized by using data throughout time, for example information of a patient during his existence at the hospital center is used and requested in a period that does not exceed at least two or three times a day, which makes our case and our solution like the active information with a rate of use equal to $100 \%$. We can divide this information into a database that will be indexed by 1 (Data $)$, but the other information will be distributed according to their rate of use $\mathbf{n}$ over databases Data $_{\mathrm{i}}(\mathrm{i}=100-\mathrm{n}+1)$ (Figure 4). For this, sub-division of information into many databases $\left(\right.$ Data $_{1}$, Data $_{2}, \ldots$, Data $_{n}$ ) that have the same structure of tables must ensure a good performance of a such HIS, which yields a stability of the execution time of queries and depends only on the number of beds that can be assured by such a hospital center.

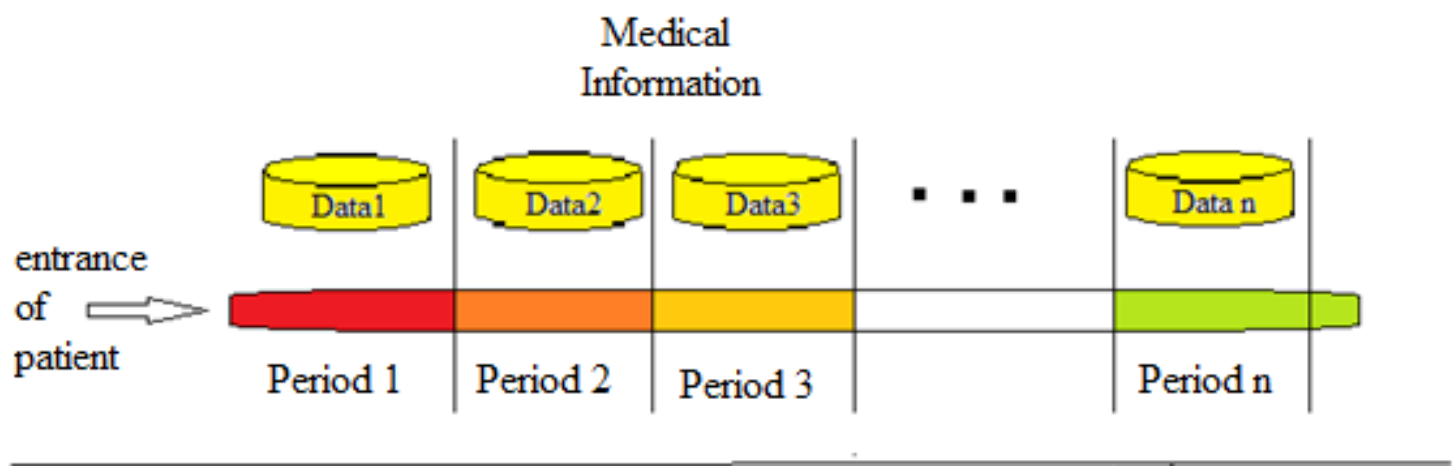

Figure 4 Partition of information according to the rate of use 
The period and the partition of databases in some hospital centers is a free choice for the hospital according to the performance between the evolution of technology and the amount of information to ensure a good performance for the manipulation of information.

Remark: Period $i$ in figure 4 is equivalent to the number $\mathrm{n}$ of rate of use of information in the databases Data $_{\mathrm{i}}(\mathrm{i}=100-\mathrm{n}+1)$.

\section{CONSTANT ENTITIES OF HIS}

Entities of HIS for a medical subsystem are classified as constant entities and have direct relation (association) to the patient's information. This set of constants entities are integrated into a relational data base management system (RDBMS) by one database called DATAPRIX. Here are some tables of DATAPRIX:

DIAGNOSE(\#CODE varchar(10), DESCRIP varchar(200), USER varchar(20), GEL bit) =Entity information of ICD10.

DOCTORS(\#ADMI varchar(3), NOM varchar(50), \#CODESPECIALITE varchar(3), ADRESSE $\operatorname{varchar}(200)$, TEL $\operatorname{varchar}(20)$, ACCOUNT $\operatorname{varchar}(10), \ldots)=$ Entity of personal information of doctors, we must mention that the attribute ACCOUNT is an information which relates doctor to the accounting subsystem.

ASSURANCE(\#ADMI varchar(3), NOM varchar(50), ADRESSE varchar(200), TEL $\operatorname{varchar}(20)$, ACCOUNT varchar(10), COVER float, ...)=Entity of information about insurance companies.

LBDAT(\#CODE varchar(10), DESCRIP varchar(200), USER varchar(20), LBL float, GEL bit, CNOMLAB varchar(10), ACCOUNT varchar(10)...)=Entity of laboratory information (CBCD, $\mathrm{WBC}, \mathrm{RBC}, \ldots)$.

ECDAT(\#CODE varchar(10), DESCRIP varchar(200), USER varchar(20), ECK float, ECAPP float, GEL bit, ACCOUNT varchar(10)...)=Entity of information ECG, EEG, ECC.. , their use indicates a coefficient ECK of how many times it will be payed to doctor. And another ECAAP will be payed to hospital.

OPDAT(\#CODE varchar(10), DESCRIP varchar(200), USER varchar(20), OPO float, OPK float, OPR float, GEL bit, ACCOUNT varchar(10)...)=Entity of operations information (example: Code=A9000L, Descrip=Drainage external ear, abscess or hematoma: simple)

RDDAT(\#CODE varchar(10), DESCRIP varchar(200), USER varchar(20),2 RDR float, ECAPP float, GEL bit, ACCOUNT varchar(10)...)=Entity of Radiology Information (MANDIBLE, UNILATERAL, FACIAL BONES, ...)

PTDAT(\#CODE varchar(10), DESCRIP varchar(200), USER varchar(20), PTA float, GEL bit, ACCOUNT $\operatorname{varchar}(10) \ldots$ ) = Entity of pathological information (BRAIN/MENINGES,TUMOR RESECTION, ESOPHAGUS,PARTIAL/TOTAL RESECTION...)

LITS(\#CODE varchar(10), DESCRIP varchar(200), USER varchar(20), CODEDEPARTEMENT varchar(2), GEL bit, TEL varchar(10), ADMI varchar(10))=Entity of information of rooms and beds in a hospital, the code 201A indicates the bed A and the room 201. 
DEPARTEMENT(\#CODEDEPARTEMENT varchar(3), DESCRIP varchar(200), USER $\operatorname{varchar}(20)$, GEL bit)=Entity for information about the departments in a hospital $(\mathrm{CCU}, \mathrm{ICU}, \ldots)$.

SPECIALITE(\#CODESPECIALITE varchar(3), DESCRIP varchar(200), USER varchar(20), GEL bit) $=$ Entity information of medical specialties (general, genichologue, ...)

The tables of constant entities, for example the set of classified information that indicates the results of medical laboratory (like $\mathrm{CBC}, \mathrm{WBC} .$. ) is classified as constant information, as well as the same applies for the medical information, pharmacology information, ICD10 information, radiology information, and the information of insurance companies... For this reason, we must put this set of information in only one database (Figure 5) called (DataPrix). The medical information gives rise to relations with the set of clients that are subject to the subsystem of storage, its rate of use in the subsystem is greater than its rate of use in the medical subsystems. Hence, we should integrate the set of medical information in the database assuring the set of common information of the subsystem of storage indicated in Figure 5 by the name DataStoc.

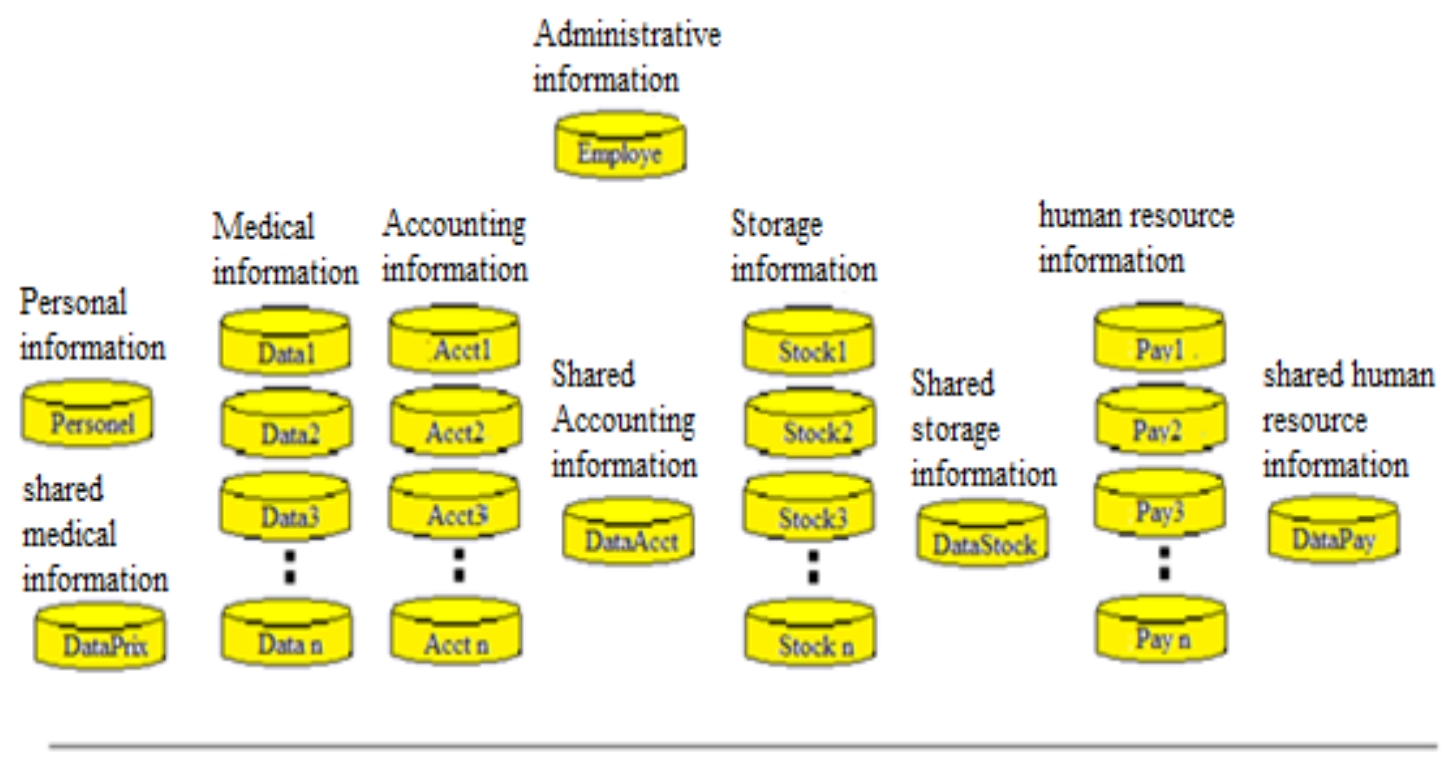

Figure 5 Distribution of database in HIS

The relations between patients and the common constant information as indicated in Figure 6 . 


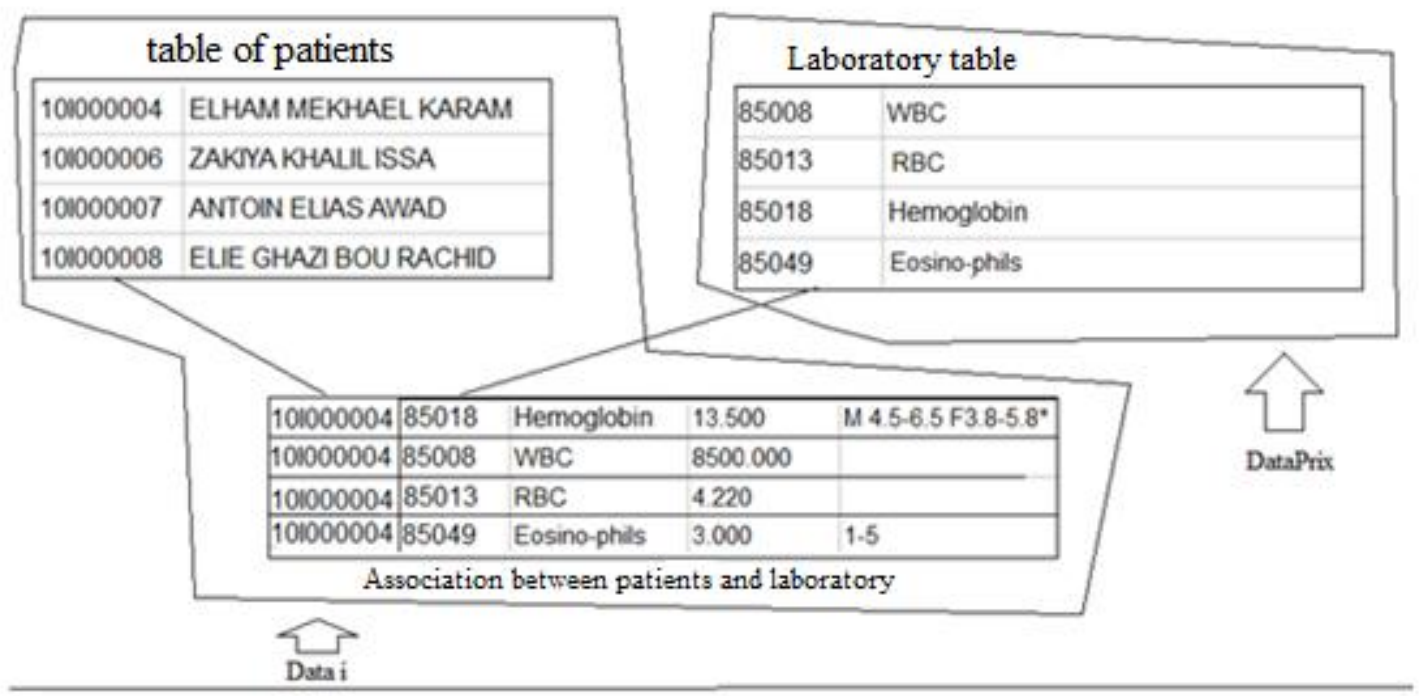

Figure 6 Tables DATAPRIX and DATA and the relations between them

\section{Personal information OF PATIENTS:}

The entity of personal information of patients is an entity that assures a link with each entry of the patient which is either entry or departure by one or more days in hospital, or an entry by a specific treatment in the emergency service, or by a radiology, or laboratory analysis. This entity must be integrated in an intermediate database called DATA, and that which should assure all the necessary information to identify a unique person.

PERSONAL(\#ADMI varchar(10), MIDDLENAME varchar(50), FIRSTNAME varchar(50), FATHER varchar(50), FAMILYNAME varchar(1), MOTHER varchar(50), ..).

\subsection{Table DATAi information}

The table DATAi must include all the following patients' information:

- PATIENT(\#ADMI varchar(10), link with personal information, link with doctor who treats him, link with insurance company, date in, date out, link with entrance of ICD10, link with exit of ICD10, information of Discharge, Summary...).

- Financial information of patient:

TRANS1(ADMI, patient identity, CARACT varchar(1), SERIAL int, LIGNE int, link with information into the constant database in DATAPRIX, the price according to an agreement with the insurance company...), we must indicate that (ADMI, CARACT, SERIAL, LIGNE) is the primary key of table TRANS1. On the other hand, adding information from DATAPRIX into TRANS1 allows to make the largest amount of queries that provide a good performance for the execution of a query.

- Information of laboratory results of a patient:

TRLAB(ADMI, patient identity, CARACT varchar(1), SERIAL int, LIGNE int, relation with information into the constant database in DATAPRIX, RESULTAT varchar(200)), we must indicate that (ADMI, CARACT, SERIAL, LIGNE) is the primary key of table TRLAB. On the 
other hand, adding information from DATAPRIX into TRLAB allows to make the largest amount of queries which provides a good performance for the execution of a query.

TRANSO $=$ information of doctor treating the patient.

\section{QUERIES}

To make a query for a client we must save the set of names of databases into a cursor called « qprogram » with indicator called «checkbox » (Figure 7) to let the client select the set of databases requested by his/her query, then by connecting to the server we can execute this algorithm that is written using the language Visual FoxPro (vfp9.0).

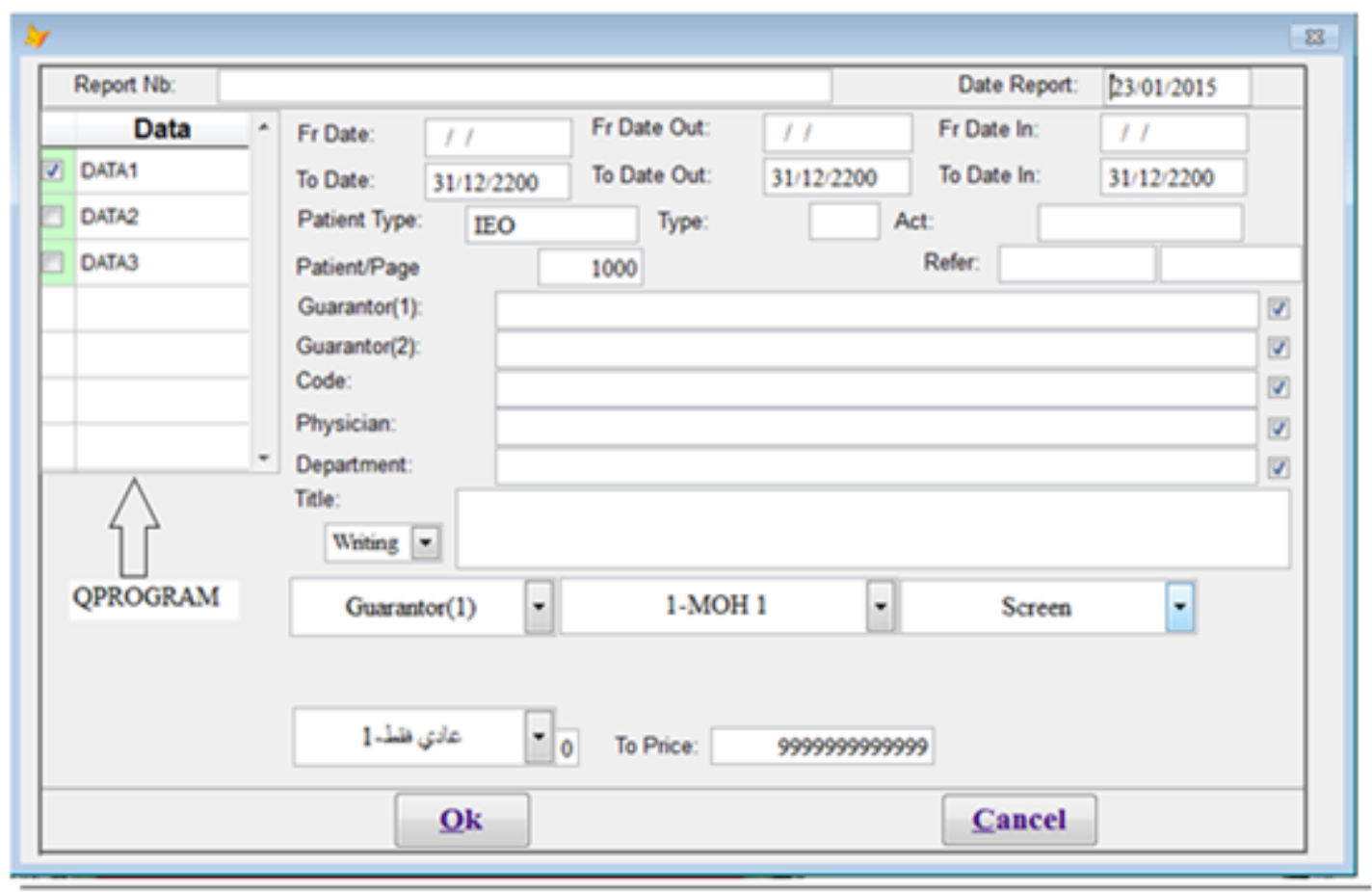

Figure 7 Interface to indicate the filter conditions for a query (done by software CheBHosp)

Algorithm for making a query on one or more databases:

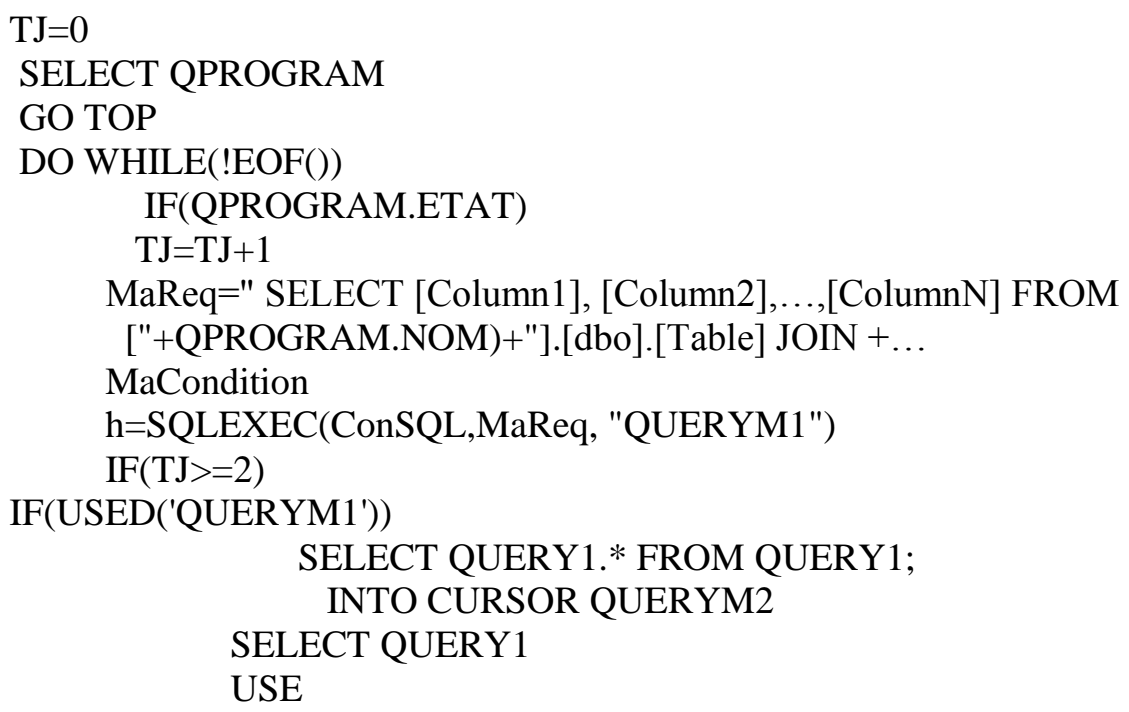




\section{SELECT QUERYM1.* FROM QUERYM1; \\ UNION ALL(SELECT QUERYM2.* FROM QUERYM2); \\ INTO CURSOR QUERY1 READWRITE}

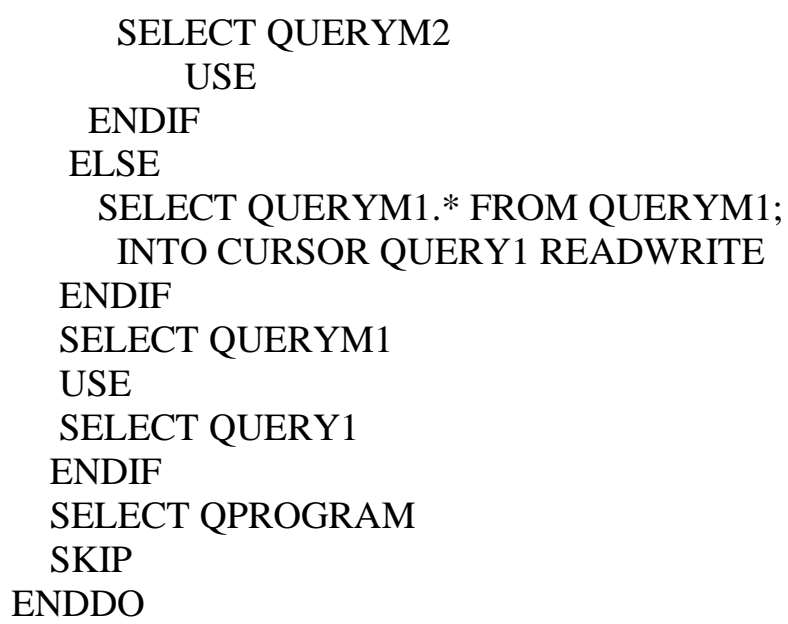

Algorithm for transferring the data between two tables DATA $\mathrm{D}_{i}$ et DATA

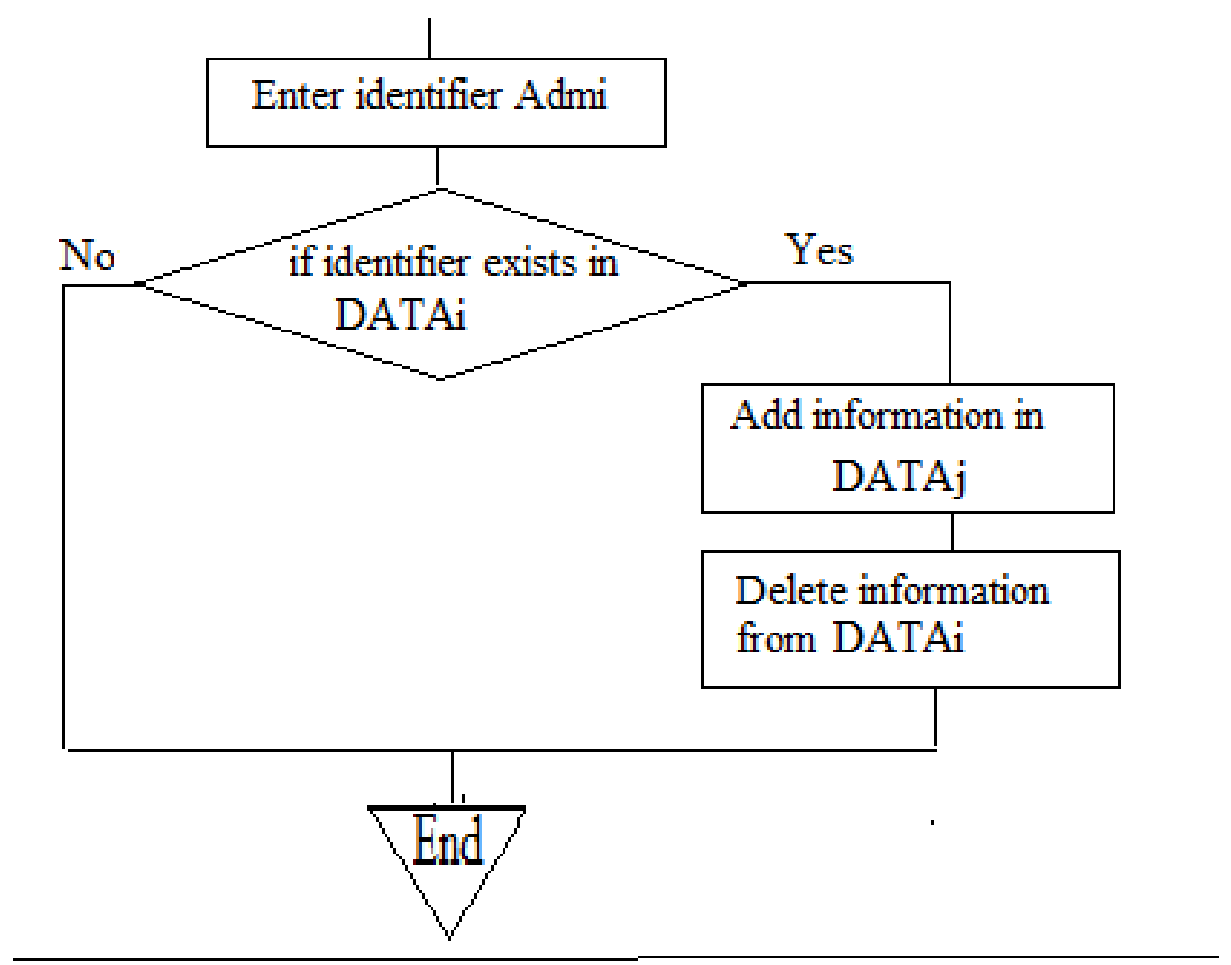

\section{Conclusion}

The domain of nowadays health care is seen as a domain that should be computerized with a large scale. The complexity [24]. of medical information is an obvious brake[16,18]. It seems clear nowadays that the health information systems must evolve in order to incorporate the semantic $[25,28]$, not like an ad-hoc evolution, but as a fundamental change of the architecture in the heart of information system. Hence, our suggestion is to integrate and partition the information 
according to the rate of use, is an encouraging solution in the future, namely for the huge amount of information that allow hospitals to reduce the expenses on material technology, and which permits a server of good performance to answer all the questions [17, 21,22,23] put by a hospital information system. The partition of this information into a set of databases assures a large security for the storage of information, and allows human resources department [26] to apply in an effective way the "job description" of employees.

\section{REFERENCES}

[1] Fieschi M, (2003), “ Les données du patient partagées : la culture du partage et de la qualité des informations pour améliorer la qualité des soins ", Rapport au ministre de la santé, available on website : http://www.d-mp.org/docs/Rapport fieschi.pdf, consult in 20 octobre 2007.

[2] Patrice Degoulet \& Marius Fieschi (1998), “Informatique médicale ”, Elsevier Masson.

[3] Christian Lovis, Stéphane Spahni, Nicolas Cassoni-Schoellhammer \& Antoine Geissbuhler (2006), "Comprehensive management of the access to a component-based healthcare information system", studies in health technology and informatics, vol. 124, pages 251_256, 2006. :2006tn.

[4] Weller, \& Bart (2010), "Beginning SQL Server Modeling”, ISBN 978-1-4302-2752-6, eBook.

[5] Sales Harkins, Susan, Reid, \& Martin (2002), “Access to SQL Server 2002” , ISBN 978-1-43021573-8,eBook.

[6] Seidl M, Scholz M, Huemer C, \& Kappel G (2014), “UML @ Classroom An Introduction to ObjectOriented Modeling”, ISBN 978-3-319-12741-5, eBook.

[7] Artjom Klein, Arash Shaban-Nejad, Gregory W Rose, Alan J Forster, David L Buckeridge, \& Christpher JO Baker (2013), "Semantic quering of relational data for clinical intelligence: a semanticbased approach", Journal of Biomedical Semantics March 2013, pp. 4-9.

[8] Steve Langer, \& Jihong Wang (1996), "User and system interface issues in the purchase of imaging and information systems", Journal of Digital Imaging August 1996, Volume 9, Issue 3, pp 113-118.

[9] Erik K Fromme, Tawni Kenworthy-Heinige, \& Michelle Hribar (2010), "Developing an easy-to-use tablet computer application for assessing patient-reported outcomes in patients with cancer", Supportive Cae in Cancer June 2011, Volume 19, Issue 6, PP 815-822.

[10] Wright, \& Heather (2006), "Begininng Visual Basic 2005 Express Edition”, ISBN 978-1-59059-6227, eBook.

[11] Thomsen, \& Carsten (2001), "Database Programming With Visual Basic .NET 2001", ISBN 978-14302-1132-7, eBook.

[12] American Standards for Testing and Materials (ASTM) (200), "Standard Guide for Properties of a Universal Healthcare Identifier (UHID)", Designation: E1714-95, Volume 14.01, issued June 2000.

[13] C.Oumar Bagayoko, J.-C. Dufour, P. Avillach, C. Quantin, \& M. Fieschi (2008), "Reflections on the patient identification in the Healthcare Information Systems", ELSEVIER MASSON, IRBM 29 (2008) 302-309.

[14] Bijalwan, Vishwanath, et al. "KNN based Machine Learning Approach for Text and Document Mining." International Journal of Database Theory and Application 7.1 (2014): 61-70.

[15] Semwal, Vijay Bhaskar, et al. "Accurate location estimation of moving object with energy constraint $\&$ adaptive update algorithms to save data." arXiv preprint arXiv:1108.1321 (2011).

[16] Sati, Meenakshi, et al. "A Fault-Tolerant Mobile Computing Model Based On Scalable Replica." IJIMAI 2.6 (2014): 58-68.

[17] Kumar, K. Susheel, et al. "Sports video summarization using priority curve algorithm." International Journal on Computer Science \& Engineering 2.9 (2010): 2996-3002.

[18] Kumari, Pinki, and Abhishek Vaish. "Brainwave's energy feature extraction using wavelet transform." Electrical, Electronics and Computer Science (SCEECS), 2014 IEEE Students' Conference on. IEEE, 2014.

[19] Susheel Kumar, K., et al. "Generating 3 D Model Using 2 D Images of an Object." International Journal of Engineering Science and Technology 3.1 (2011).

[20] Bhaskar-Semwal, V., et al. "Accurate location estimation of moving object In Wireless Sensor network." International Journal of Interactive Multimedia and Artificial Intelligence 1.4 (2011).

[21] Gupta, Jay Prakash, et al. "Human activity recognition using gait pattern."International Journal of Computer Vision and Image Processing (IJCVIP) 3.3 (2013): 31-53. 
[22] Kumari, Pinki, and Abhishek Vaish. "Instant Face detection and attributes recognition." International Journal of Advanced Computer Science and Applications (2011).

[23] Bijalwan, Vishwanath, et al. "Machine learning approach for text and document mining." arXiv preprint arXiv:1406.1580 (2014).

[24] Kumar, K. Susheel, Vijay Bhaskar Semwal, and R. C. Tripathi. "Real time face recognition using adaboost improved fast PCA algorithm." arXiv preprint arXiv:1108.1353 (2011).

[25] Kumari, Pinki, and Abhishek Vaish. "A Comparative study of Machine Learning algorithms for Emotion State Recognition through Physiological signal."Advances in Intelligent Systems and Computing 236 (2013).

[26] Gupta, Jay Prakash, et al. "Analysis of Gait Pattern to Recognize the Human Activities." arXiv preprint arXiv:1407.4867 (2014).

[27] Kumari, Pinki, Santosh Kumar, and Abhishek Vaish. "Feature extraction using emprical mode decomposition for biometric system." Signal Propagation and Computer Technology (ICSPCT), 2014 International Conference on. IEEE, 2014.

[28] Vaish, Abhishek, and Pinki Kumari. "A Comparative Study on Machine Learning Algorithms in Emotion State Recognition Using ECG." Proceedings of the Second International Conference on Soft Computing for Problem Solving (SocProS 2012), December 28-30, 2012. Springer India, 2014. 